\title{
Re-conceptualizing Hegelian Master-Slave Dialectic as Diachronic Systems Theory of Inter-societal Relations*
}

\author{
Kwon, Gi Bung \\ (Kyunghee University)
}

\section{$\langle$ CONTENTS〉}

I . Introduction

II. Critical Analysis of Systems

Theory in International Relations

III. Reformulating Hegel's Mater-Slave

Dialectic as Diachronic Inter-societal

Systems Theory

- Keyword: Diachronic systems theory, International Relations, Hegelian dialectic of recognition, Master and slave, Autopoietic political theory

\section{【ABSTRACT】}

The term "system" is so widely used in ordinary language that its precise meaning is all but lost. Those who use it tend to be not very clear about what kinds of system they have in mind in their usage. Most of them conflate one type of system with others without heeding to their distinctive conceptual requirements. If the concept of system is to be not just a descriptive but an explanatory one of social relations, each type of system has to be taken as a whole package, including its structural requirements. Otherwise, its conceptual components cannot have a non-contradictory internal relationship among them. The necessary internal relationship among system components have important theoretical implications for the systems theory in International Relations, specifically in regards to its epistemological and ontological issues. To address

*The author expresses his gratitude to the anonymous readers whose constructive comments have enormously helped the paper's refinement although the remaining shortcomings are still the author's responsibility. 
these implications, this paper first analyses the theoretical issue of boundary delineation. When carefully examined, it turns out that no theoretically sound method of determining system's boundary is found in the prevalent positivistic conceptualization of system. Only when we succeed in overcoming the limitation of boundary delineation can we make use of the concept of system in the study of international relations. By carefully reconstructing Hegelian dialectic of recognition, this paper illuminates its theoretical potentiality as autopoietic political systems theory of international relations that overcomes the theoretical limitations of the prevalent positivist conceptualization of system in International Relations.

\section{I . Introduction}

The term "system" is so widely used in ordinary language that its precise meaning is all but lost. However, we can define it, at least in social sciences, roughly as a concept designating the social relations in which "the actions of several actors are meaningfully interrelated and are thus in their interconnectedness, marked off from an environment." This does not mean that the concept is an exact reflection or replication of the given relations. Like any other concepts, the concept of system simplifies the complex reality into a recognizable pattern for a schematic understanding and explanation of the objects under study. ${ }^{2)}$ Whether we can talk of a system in social relations, therefore, depends on how we answer the question: For what purpose does the system reduce the complexity of reality? What is important in this regard is the "meaningfulness" of interactions as the above definition states. How we conceptualize it determines the kinds of system we postulate in social sciences. On account of this, we may be able to say that no determinate principle is found in the conceptualization of system in social sciences.

Despite the indeterminacy of system in principle, the practitioners generally agree that insofar as certain conceptual components (i.e., agents, interactions, and structure) are identified, the concept of system can be used not just as a descriptive but also as an

1) Niklas Luhmann, The Differentiation of Society, trans. Stephen Holmes and Charles Larmore (New York: Columbia University Press, 1982), p.70.

2) See, Niklas Luhmann, Social Systems, trans. John Bednarz Jr. and Dirk Baecker (Stanford, CA: Stanford University Press, 1995). 
explanatory concept for the study of social relations. Those who use it, however, tend to be not very clear about what kinds of system they have in mind in their usage. Most of them conflate one type of system with others without heeding to their distinctive conceptual (or structural) requirements. When eclectically combined, the systems theory loses its logical coherence; it becomes no more than a descriptive device. If the concept of system is to be not just a descriptive but an explanatory one of social relations, each type of system has to be taken as a whole package, including its structural requirements. Otherwise, its conceptual components cannot have a non-contradictory internal relationship between them. Then, the system becomes theoretically groundless, meaning that its conceptual components do not hold together logically. Since each of these constituent components does not stand alone as an independent category having an external relation to the others in the system, we can differentiate systems in terms of the logical relatedness of system components. In this vein, Niklas Luhmann identifies three distinct types of system prevalently used in social sciences, each of which cannot be conflated with others without losing its conceptual meaningfulness. He classifies them by the principles underlying the reduction of complex reality: that is, the systemic criteria of self-selection and boundary-formation. ${ }^{3)}$

The necessary internal relationship among system components have important theoretical implications for the systems theory in International Relations, specifically in regards to its epistemological and ontological issues. To address these implications, this paper first analyses the theoretical issue of boundary delineation. When carefully examined, it turns out that no theoretically sound method of determining system's boundary is found in the prevalent positivistic conceptualization of system. To remedy the theoretical deficiency, this paper maintains that the concept of system should be properly re-conceptualized in line with Hegelian dialectic of recognition. Only when we succeed in overcoming the limitation of boundary delineation can we make use of the concept of system in the study of international relations. To elaborate this theoretical proposition, this paper dissects Hegel's dialectic of Master-Slave in terms of systems theory. It argues that the dialectic of recognition provides alternative conceptualizations of systems in international relations, despite the fact that it does so in an inchoate form. By carefully reconstructing it, this paper illuminates its theoretical potentiality as autopoietic political systems theory of international relations that overcomes the theoretical limitations of the prevalent positivist conceptualization of system in International Relations.

3) See, Luhmann, The Differentiation of Society, pp.69-89. 


\section{II . Critical Analysis of Systems Theory in International Relations}

In the generic sense, the concept of system has three components: units, interactions, and boundary. A system is postulated where units interact with each other within a certain boundary. ${ }^{4)}$ This somewhat commonsensical conception papers over its thorny epistemological issues, however. Of particular relevance is the problem that the practitioners face in their conceptualization of system: the issue of boundary. ${ }^{5}$ Where or how can we draw a line between systems? Unless we have a theoretically defensible answer to this question, we can postulate only one type of system in the world: i.e., all encompassing system which includes all the living and non-living creatures and microand macro-interactions. Without a differentiating concept, therefore, either talking of a system in social relations is meaningless or the concept of system becomes unmanageable. The encompassing system is too complex to be a useful conceptual device for social relations.

Furthermore, their nature of "meaning objects" makes the boundary issue particularly acute when the concept of system is applied to the study of social objects. What is germane to the discussion at hand is the fact that whereas a system of natural objects is boundary-drawn by "causal" relations between natural objects, the boundary of social objects cannot be drawn likewise. That is because a social system arises from and resides in the interactions among "socially constructed objects," which mean that they are already embedded in another higher category of society. Consequently, a social system cannot be conceptualized as naturally arising from positively identifiable units and their interactions, all of which are ontologically independent. It is already impregnated in the given "society" by which the actors are constructed in the first place and their interactions are produced and reproduced. If an investigator wants to discover a system in the interactions of actors (units), therefore, s/he has first to grasp the underlying "social" structures of the society and the type of actors who are constituted by it beforehand. Only afterward can s/he define the system as a particular type of interactions among the socially constructed actors. This theoretical point can be broached and further clarified when we examine the question of boundary.

As mentioned, the systemness of a system is a "theoretical" construct to describe and

4) See, Kenneth Waltz, Theory of International Politics (Reading, Massachusetts: Addison-Wesley Publishing Company, 1979), p.40.

5) On the issue of boundary delineation for the meaningful use of the concept of system in international relations, see Friedrich Kratochwil, "On System, Boundaries, and Territoriality: An Inquiry into the Formation of the State System," World Politics, vol.39 (Oct. 1986), pp.27-52. 
explain otherwise unknowledgeable social objects (or phenomena). This does not mean that a system is a purely mental construct that can be invented at will by an observer independent from the social objects. Like any other social concepts and categories, it has to be corroborated by empirical facts. Otherwise, it loses its meaning and relevance as a social concept. In other words, it has to designate specific social objects and their relations that, in turn, bring out the concept of system whenever they are present. ${ }^{6}$ On what basis does an investigator bestow systemness on the social objects he observes, then? While the systemness of a system resides in the interactions of units, it is not readily observable from them. The units have to be first delineated and their interactions have to be identified for the existence of a system. Those processes presuppose necessarily a generative principle that structures the given society. How else can we know what exists unless we have a criteria to identify agents and actions beforehand? In International Relations, Kenneth Waltz's important theoretical contribution lies in this regard: the idea that the concept of structure is an essential, necessary corollary for the concept of system. That is, structure gives a system a definite characteristics (or systemness); system cannot be delineated without it."

Although it is widely accepted by the positivists, Waltzian conception of system does not provide a satisfactory answer to the question of boundary. ${ }^{8}$ As mentioned above, the theoretically necessary condition for the postulation of system is that system has to be inferred from the interactions of "agents" for it does not reside in the nature of things. This being the case, an important issue that needs to be addressed is: When the agents are not known beforehand and insofar as agents' activities are not a priori bounded, on what basis can an investigator draw a boundary of a system? Unless there preexists something that determines the identity of agents, simple observation will not reveal whom the agents are, what kinds of actions the agents perform, and whether the actions are clustered enough to form a bounded realm of activities. If structure is, by definition, the category that organizes social interactions among agents into a system, that identity-giving something should be known a priori to determine those questions.

6) See, Derek Layder, The Realist Image In Social Science (New York: St. Martin's Press, 1990), particularly pp.42-65.

7) Waltz states: "The structure is the system-wide component that makes it possible to think of the system as a whole." Waltz, The Theory of International Politics, p.79.

8) For positivism's influence on International Relations, see Mark A. Neufeld, The Restructuring of International Relations Theory (Cambridge: Cambridge University Press, 1995), pp.32-8. Particularly, he identifies three tenets of philosophical positivism that are uncritically imported to IR: truth as correspondence, methodological unity of science, and value-free nature of scientific knowledge. 
This means that another type of structure is already presupposed in the case of the Waltzian system: this time, "social" structure which exists prior to the system and systemic units (agents) as an ontologically preexisting entity.

What Waltz needs for his conceptualization of system to be theoretically viable, particularly to answer the question of boundary, is to find a way for the identification of systemic units. The identification of agents, it is shown, requires an ontologically independent category of "social structure." Having failed to do so, Waltz is certainly liable to be criticized as providing another reductionist conceptualization of structure, notwithstanding his claim otherwise. ${ }^{9)}$ If the social structure is acknowledged as being presupposed, however, there is no logical problem in arguing that a systemic structure constrains what the agents do and that the structure resides in the agents' interactions, but is separate from the agents' own characteristics. The statement is logically acceptable because the identity of agents is already formed by the pre-existing social structure. The interactions that agents produce, therefore, are already determined ones in the sense that their intentions (goals) and means available for the actions are largely fixed or at least reduced to one-dimensional one. A systemic boundary then is also determinable around the clustered actions. A system is formed and identifiable.

In other words, the construction of a system is possible precisely because the agent identity is already determined, hence the actions. If they are determined, there will be identifiable clusters of agent actions distinct from other types of actions. Once the clusters of actions are identified, there is a system which has a clear delineating boundary from other systems. To infer further, insofar as a system is constructed around a particular type of actions and agents, it is certainly a possibility that, like Waltz's conceptualization of structure, a "systemic" structure resides in the "positions" that agents occupy in relation to the other agents. For the position among agents is only "apparent" systemic property that might have an impact on the actions of agents against others, whereas other possible sources of structure are already included in the category of "social" structure, those that have direct relationships with the agent identity formation: i.e., rules, norms, and generative principles.

The reason why the positivist conception of system and structure, including the Waltzian one, requires presupposing the ontologically independent "social" structure as

9) Wendt's criticism of Waltz is exactly on that point. Alexander Wendt, "The Agent-Structure Problem in International Relations Theory," International Organization, vol.41 (Summer 1987), pp.335-70. For Waltz's own retort to his critics, see Kenneth N. Waltz, "Reflection on Theory of International Politics: A Response to My Critics," in Robert O. Koehane, ed., Neorealism and Its Critics (New York: Columbia University Press, 1986), pp.322-45. 
a necessary category has to do with its logical impossibility to find a plausible way to delineate system boundary. Ontologically speaking, a system's systemness resides in the nature of agents and their "determined" interactions. This is the crucial ontological fact of the category of system, which the positivistic structural systems theory does not thematize, but the practitioners often make use of and rely upon consciously or unconsciously in drawing system boundary. Instead of discussing the ontological issue directly, we first look into the general practices in order to lay it bare what is presupposed in their boundary drawing.

When we casually observe the general practices of systems theory in social sciences, we can discern two boundary-identifying criteria that are employed to delineate a system: the types of objects of interaction and locality. When we talk of U.S. political system, Canadian economic system, Great Britain's social system, international trade system, and international security system, etc., we are postulating geographically bounded systems that are formed around particular types of agents, whether they are states, business corporations, international organizations, or a particular country's citizens, etc. Of the two, however, locality is only for the expediency of study. It is an arbitrarily chosen criterion, especially in social phenomenon. If, as the definition of system dictates, units and interactions are the only determinants which allow the postulation of a system, there should not be any other system formation variable than those two, logically speaking. This means that locality cannot be a boundary drawing principle. It may be the case that systems are generally bounded geographically and therefore have locality. This locality however is a derivative effect of the system formed through agent interactions. In other words, it results from the fact that agent interactions are in most cases constrained geographically because the distance between agents is a limiting factor in their interactions, if not overcome by technology. The general practices thus have only one logically sound criterion of boundary determination: that is, the types of agent. The use of agent type as the sole criterion is problematic, however. The problem lies in the fact that agents, especially human agents, do not act as a single purpose agent. Even such single purpose agents like ants and bees, which may be conceptualized as performing one function, should be assigned different purposes or functions, depending upon the size and kind of system an investigator conceptualizes as the subject of study. That is, the function or purpose is not inherent in the agent nature, which means that a system does not arise from the latter, but is teleologically imposed by an investigator. This is more so in the case of human agents, who perform multiple functions simultaneously.

Notwithstanding the theoretical and methodological difficulties, the general practices 
draw the boundary around the object of their study arbitrarily. The arbitrariness, however, is not purely arbitrary to the extent that they use the medium of interaction as an additional criterion of boundary determination to the agent types even though they do so for practical, not for theoretical reason. Thus, a monetary system is constructed around money involved in the agent interactions; a trade system around trade-goods; and an electoral system around electoral activities, etc. To put it into a more general category, these may be called "signifiers." When the two, the agent types and the mediums (signifiers), are combined, the former's inherent multiplicity is reduced into one-dimensional one; thereby its indeterminacy in boundary drawing is avoided. For it is plausible that if a particular actor's (agent's) action is in its nature "purposeful" or "instrumental," it is likely that agent intentions (hence action-goals) are at least partly constituted by the available means; their actions, as a result, will be largely determined by the mediums of interaction. If money is the single determinant medium of interaction among certain groups of actors, for instance, there will be no other incentives for action but money-making. Then, their actions will be bounded by the single purpose of money-making. By a necessary corollary, the entailing interactions will be certainly delineated from other kinds of purposeful actions, hence a bounded system: those interactions performed by agents for monetary incentives.

The problem that the author finds in the general practices, therefore, is not the reduction itself, but that they do not explicitly recognize the underlying mechanism of system construction, thereby blind to the possible fundamental transformations or variations of system which may arise from the changes of agent identity. What if, for instance, the so-called economic man does not act and react to the monetary incentives? What if the bureaucrats become corrupt all of sudden and they think only of their fortune? These questions should not be answered in an ad hoc way as an abnormality that cannot be explained within the theory itself, as is the case of all the synchronic positivist conceptualization of system. These have to be within the gambit of a systemic theory as a potentiality, that is, as theoretical possibilities from the same premises that are utilized in the construction of system. ${ }^{10)}$

One easy way to achieve the endogenization of variables, the one generally accepted method, is to problematize the actor assumption and to accommodate its possible variations within the synchronic systems theory premises. ${ }^{11}$ The crucial theoretical

10) For the necessity of diachronic system theory that incorporates structural transformations as its potentiality in international relations, see John G. Ruggie, "Continuity and Transformation in the World Politics: Towards a Neorealist Synthesis," World Politics, vol.35 (Summer 1983), pp.261-85.

11) For the examples of the positivist response to the issue of system change see, Barry Buzan, Charles 
problem with this relativization of agent, however, is how it is possible to determine which agent type (or types) is selected out as the one that undergirds the entailing system and its structure and what the relationship with other potentialities is. Without explaining this, the system theory again either becomes post hoc or has no choice but to rely upon the "predictability" of the positivistic conception of theory test as its justification. Either way it is unsatisfactory, because theory degenerates in the first into "understanding"; in the second it has no relationship with "understanding." Theory is more than "understanding" because it has to be empirically supported, that is, to be put into practice and corroborated by the result; but it also requires the latter because without it theory is no better than fortune telling. ${ }^{12)}$

Because of these methodological requirements of social theory, the criterion of agent selection has to be thematized in the construction of systems theory and justification for it has to be provided if a certain type of agent is selected out. Only then can we avoid both of the pitfalls because it is then possible to delineate the phenomenon that is logically derivable from the theoretical presuppositions from ones that are not. This delineation provides the testability of the theory and works back to the actor assumption in the direction of revision that incorporates the unexpected. It then leaves no abnormality outside of the systemic theory by providing justification for the selection without excluding the possibility of critical re-examination. ${ }^{13)}$

Hence, a crucial step in the construction of diachronic systems theory that does not exogenize the sources of systemic change, in addition to the requirement that it can be boundary-delineated, is to provide an agent identity formation theory that can justify a particular assumption of an actor-type in a system. The justification cannot come from a generative rule of systemic structure, which is the other side of the same coin of the actor assumption as is indicated above. Otherwise, it becomes a tautology. We,

Jones, and Richard Little, The Logic of Anarchy: Neorealism to Structural Realism (New York: Columbia University Press, 1993). Systemic transformations are conceptualized as derivatives of constituent actors, intensity of interactions, or environmental changes.

12) For the difference between understanding and causal explanation and the latter's distinctive role in social sciences, see Martin Hollis and Steve Smith, Explaining and Understanding International Relations (New York: Oxford University Press, 1990).

13) The criticizability of the actor assumption comes certainly from empirical evidence. Here the empirical evidence, however, is not the apparent phenomena as the positivists conceptualize because there is no empirical evidence that is not theoretically impregnated. It is provided by theoretical possibilities that follow from ontological presuppositions upon which the theory is built. The question here is which one better explains the phenomenon at hand; that is "heuristic value" in the Lakatosian sense. See, Imre Lakatos, "Falsification and the Methodology of Scientific Research Programmes," in Imre Lakatos and Alan Musgrave, ed., Criticism and the Growth of Knowledge (Cambridge: Cambridge University Press, 1970), pp.91-196. 
therefore, have to find an original source of the possible changes of actor's selfconception of action. Here the general practice of the utilization of a medium of interaction (signifier) points to a possible answer. If this proposition holds, it means that the medium of interaction is an ontologically necessary category for the diachronic systems theory, particularly for its boundary drawing. Once its ontological necessity is accepted, it also follows that a system exists already within a social system. For the medium of interaction cannot stand alone, but works as a medium only within the realm where its intermediarity is accepted among social actors, just as any signifier has meaning only within a language.

The above epistemologically derived inference needs to be explicitly recognized and problematized for the construction of any systemic theory. It has to be recognized because the system is an arbitrary construction otherwise; problematized, because any autopoietic systems theory that attempts to embody within itself the logic of transformation has to make room for possible historical transformations or multiple utilization of signifiers and their entailing systemic effects. ${ }^{14}$ By investigating the nature of the signifier, in other words, we can have theoretically sound ontological bases upon which we can draw a system boundary. By tracing its historical variations and their implications on the structures of emerging systems, we will be able to explain the systemic transformations. Hegelian dialectic of recognition is the exemplary theory that embodies these theoretical insights in parts and parcels. ${ }^{15}$ When carefully reconstructed, it has the potential to lay the foundation for a diachronic systems theory of intersocietal relations big and small.

14) The key to the transformation lies in the distinctive nature of signification: that is, signifier's inherent overdetermination. For its specific implication on the actor identity, see, Ernesto Laclau and Chantal Mouffe, Hegemony and Socialist Strategy: Toward a Radical Democratic Politics, trans. Winston Moore and Paul Cammack (London: Verso, 1985), pp.105-114.

15) The same theoretical arguments could be made with any other theorists than Hegel including Marx as long as the theorist takes the mediated nature of human action seriously. The author chose Hegel's dialectic of master and slave since it is judged to be full of heuristic values which have direct relevance to the contemporary international relations. Of particular importance in this regard is the fact that it points to other possible conceptualizations of systems in inter-societal relations of small and big while it also embraces the positivistic concept of system within its theoretical possibilities. Hence it allows a theoretical dialogue among theorists of different schools. 


\section{Reformulating Hegel's Mater-Slave Dialectic as Diachronic Inter-societal Systems Theory}

Being recognized by and recognizing others remain throughout the life a prime factor shaping the sort of person one is. In the first place, self-conscious beings characteristically want to be recognized as "persons"-i.e., as conscious entities that are centers of agency, not just as mere objects in the world of interest only because of their use. In the second place, they also want to be recognized as persons of a certain sort, to be thought of as having a particular identity and particular worth. Logically, this kind of assurance requires that others beings acknowledge who and what the person is. That is, you cannot assure yourself that you are a person precisely because it is doubts about your personhood that are at issue. You need others to recognize you as a person to insure yourself that you are a person. In other words, recognition is a reciprocal process requiring the existence of other human beings. ${ }^{16)}$

Unable to realize the foundational requirement of recognition, men at an undeveloped stage of history simply attempt to wrest recognition from another without reciprocating. As they are self-centered parochial beings giving no recognition of others, human beings strive to achieve mere external confirmation by imposing their force against others. Naturally the attempted imposition leads to an armed struggle, which results in the death of one or both combatants. This outcome of annihilation obviously misses the combatant's original goal of confirming their existence. Although his negation of the other has been originated by his attempt to confirm himself, the death of the adversary defeats exactly what he has sought to achieve. That is, he cannot win recognition from the dead body. What is needed is a standing negation, one in which the opponent's otherness is overcome, while the other still remains in being. ${ }^{17}$

The upshot of the master-slave relation is the mediated nature between the two parties. As slave saves his life by giving up his individuality, its relationship with the master is no longer that of equality, but that of property and material inter-mediation.

16) Brian Fay, Contemporary Philosophy of Social Sciences: A Multicultural Approach (Cambridge, Mass.: Blackwell, 1996), p.43.

17) In his seminal book Hegel, Charles Taylor discusses the dialectic of master and slave as an illustration of Hegelian style of argumentation found in the Phenomenology of Spirit. His interpretation of the dialectic illustrates nicely the richness of Hegel's Phenomenology as a potential source of insights for the conceptualization of system in social relations. For the dialectic of master and slave the author relies mainly on Taylor's interpretation. Charles Taylor, Hegel (Cambridge: Cambridge University Press, 1975), pp.148-70. For a detailed introduction to Hegel's Phenomenology of Spirit, see Jean Hyppolite, Genesis and Structure of Hegel's Phenomenology of Spirit, trans. James H. Nichols, Jr. (Ithaca, NY: Cornell University Press, 1980). 
All that the slave can do with his body is to make and prepare things for the master's consumption. For the master, therefore, the slave is only an item of the things that surround the master for use. Or the slave is no other than a tool that helps his consumption. In this situation, the master is related to the slave in no other ways than through the material reality (consumable goods). The other's independent existence being lost, the master cannot achieve the desired recognition from the slave. If the masterslave relationship is ultimately a failure of recognition for the master, it has other meanings on the part of the slave. It lays a foundation from which the slave prepares himself for the ultimate success of achieving recognition. From the inhumane subjugated relationship slowly takes place a reversal of fortune.

For Hegel, there are two crucial factors that induce self-centered individuals to the enlightening moment of discovering and actualizing the universal in themselves and for themselves, which is the ultimate goal of human development. One is the fear of death; the other disciplined work. The prospect of death shakes individuals loose from all the particularities of their life. In ordinary life human-beings are too absorbed in their dayto-day particular activities. Only war and the danger of death can break them from the narrow preoccupations and bring them back to the universal. ${ }^{18)}$ Death shows them that all the external particularities in their life are necessarily passing and destined to be negated. It invites the negation in thought, which is the true path to the universal. The reversal of fortune thus begins with the self-othering negation which the fear of death brings about. It is the slave that really suffers the fear of death, for he has been, and still is, at the mercy of another (the master). Therefore, it is the slave that is shaken loose from his particular sense of self while the victorious master is just hardened in his own world.

This immanent fear of death alone is not enough to induce the slave to the abnegation of particularity, however. It would have no more than passing effects on the slave if the latter is not occasioned with the work he is forced to perform in providing services to the master. Whereas the master enjoys the luxury of life, it is the slave who experiences the objects' resistance and independence. The master being in the world that offers him no effective resistance tends to sink back into self-absorption where he is simply a consumer and his relation to things is that of simple consumption. In contrast, the slave has to struggle with things to transform them. In so doing, he cannot help but imprint his own ideas on them. As he achieves a mastery over them sooner or later, his world is

18) For the necessity of violence and fear of death for the self-discovery, see Piotr Hoffman, Violence in Modern Philosophy (Chicago: The University of Chicago Press, 1989), pp.73-149. Also see, Paul Redding, Hegel’s Hermeneutics (Ithaca: Cornell University Press, 1996), p.110. 
made up of his own creations.

In short, the gist of the master-slave dialectic is the slave's realization of freewill and the fact that it is mediated and facilitated by the fear of death and the discipline of work. What makes the realization possible and historically necessary is Hegel's ontology of human being as essentially "embodied" being. ${ }^{19)}$ Hegel's thesis is that by controlling, making, and remaking objects, a person can establish his self as an objective feature of the world and transcend the stage in which it is simply an aspect of his inner and subjective life. ${ }^{20}$ Why is the external embodiment necessary in the development of consciousness, then? Jeremy Waldron's explanation is useful here: The subject endows the object in the material world with a purpose which is not its own. When this is done, the subject recognizes that the object is such that the only purpose it could have is a purpose given to it by him. But merely directing one's will on an object is not sufficient to embody it therein. There has to be some physical relation between the body inhabited by the subject's will and the external object in which that will is to be embodied. "Work" bridges the gap between the subjectivity of the will and the perceived eternality of the objects of the world. ${ }^{21)}$

According to Waldron, the underlying reason for the transformation of subject has to do with the logic of Hegelian dialectic. In the dialectic a being is defined only by contrasting it with something else. "If X cannot be understood without reference to non-X, then there is a sense in which non-X, far from having nothing to do with $X$, is actually essential to $X .{ }^{\left.{ }^{22}\right)}$ It is also the case with the self-definition of a human being. For instance, to define oneself as a person is, first, to mark off other bearers of rights and duties which one takes oneself to be, but then to realize that one's place in a network of other persons is itself constitutive of one's personality, and that one could not be a person except in a world of persons. Likewise, the universal consciousness through mutual recognition is a necessary outcome when the subject seeks its ultimate self-consciousness after achieving external embodiment through work. There is no other way to achieve it except the externalization of the self.

The dialectical necessity of implicating the other in one' self-identity (or the presence

19) The embodiment of human existence is the foundational premise of the dialectic of recognition. For the phenomenological meaning, see, Charles Taylor, Philosophical Arguments (Cambridge: Harvard University Press, 1995), p.21, pp.22-25.

20) Jeremy Waldron, The Right to Private Property (Oxford: Clarendon Press, 1988), p. 355.

21) In this regard, Waldron states: "When the subject labours in the world, his willing is such that it cannot be understood or explained except by making reference to the external objects of his labour; and $\cdots$ such that certain aspects of them cannot be understood or explained except by making reference to the workings of his will." Ibid., p.365.

22) Ibid., p.376. 
of non-being in being) in the process of achieving universal recognition brings into focus an important question of what the precondition is for its actualization. That is, the teleology of universal consciousness may or may not work out in itself in the history of human development insofar as it is only a "potentiality" present in the human being qua embodied being. There is no determinate reason why the dialectical necessity is actualized in the modern era unless the condition for its actualization has already been materialized. Logically speaking, at least, it has to be the case that the external embodiment is generalized enough to the extent that all the subjects are similar in their character and they can recognize each other as such. Otherwise, no condition exists for the generalization of the subject's material embodiments, hence no universality established. The private property right has played an important role in the development of this general self-understanding, Waldron argues. ${ }^{23)}$ Without the establishment of private property rights, there would not be the common denominator that not only unites them into the same category of free individuals, but also differentiates each other within it. The material condition for the actualization of mutual recognition is not present without the denominator of property rights.

The ontological independence of social structure is not just the case with the subject's identity formation. For Hegel, it is also the case with the media of interactions that intermediate the relationship with material objects and with other subjects at the underdeveloped stages of human consciousness: that is, "work" in the first and "violence" in the second. These are the means through which the subjects confirm their existence. Both of them are certainly derivative categories from the fundamental one of human subjects as being essentially "embodied" socially and materially. Their ontological independence and priority to the subjects is inferred from the fact that the subjects have no other existence except through the media: that is, without them, they are not constituted as subjects in the firs place.

If the ontological pre-existence and logical independence both of social structure and medium of interaction are accepted, we can legitimately raise a theoretical question in regards to the dialectic: Is there any necessary reason why social structure and medium of interaction in a social system should always take the forms of what the dialectic have taken. No determinate reason is found other than historical one in the Hegelian narrative. The dialectic of master-slave therefore does not have to be interpreted strictly in the literal sense. Theoretically speaking, it is quite possible to expand the Hegelian theoretical framework to other types of relations, as long as the theoretical components

23) Ibid., pp.376-377. 
and their ontological presuppositions are kept in tact. Rather in such other relations is revealed the recognitive dialectic's richness as a theory of social change and human development: that is, a diachronic system theory.

To reiterate, the key elements in the master-slave dialectic are a) human beings as being materially and socially embodied, b) violence against others as the means to confirm their existence (mediation by physical force), c) formation of the dependent relation mediated by things as an outcome of b), d) slave's achievement of material embodiment through the fear of death and the discipline of work, and e) eventual actualization of universal subjectivity aided by the social institution of property rights. Understood as such, a) and b) show that violence is inherent only in a society (or interaction system) where the self has no other way of confirming itself but by the exertion of physical force against others. ${ }^{24)}$ Possibly only in two types of society will the violent confirmation be encouraged. One is the society where physical prowess is respected and honored by the social members; the other, one where subjects are related to each other through none other than material objects, hence no interpersonal relation is possible among them.

In the latter case, violence may be a natural outcome of the relation that human beings establish with the material world. At an underdeveloped stage of human consciousness, human beings are embodied only in their physical body. Their bodily existence preoccupies them as the motive of activities. All the things surrounding them are regarded as consumable objects that need to be destroyed for their satisfaction. Insofar as the body is sustained without feeling hunger, the subject is confirmed. It is quite a short step in this situation to transpose the relation with material objects into one with other subjects, particularly when they are non-family members. That is, other subjects are likely to be treated the same way that material objects are handled for consumption. An eventual face-to-face confrontation between two or more physically embodied beings will result in the violence-mediated-relation. That is because the subjects do not know any other ways to conceptualize the interpersonal relation except that of things; hence, violence becomes the prevalent mode of interaction among the bodily-embodied subjects.

Although this is the case that Hegel has in mind at the initial confrontation between

24) Luhmann conceptualizes interaction system as the system that emerges when present individuals perceive one another as the object of his/her action, in that each one needs to adjust his/her behavior in consideration of the other's response. Organizational system is defined as the one in which membership is linked to specific conditions that are imposed on them by the organization (e.g., economic corporations). See, Luhmann, The Differentiation of Society, pp.71-2, 75. 
two subjects before the enslavement, it is not quite clear whether his argument in this regard can be maintained without presupposing another "social" relation between the confrontational subjects. The view that the physical embodiment of human beings itself naturally brings about violence against other human subjects involves a categorical transposition of relating the relation with material objects to that with human objects. If the first is to be applicable in reality, not just in analogy, to the latter, the human objects have to be reducible to things. In fact, however, the human things in the master-slave dialectic are not like those things that are immediately consumed for nourishment, but like tools with which the subject prepares goods for later consumption.

To take the human things (i.e., slave) as a property, therefore, involves an instrumental calculation on the part of the master. In contrast to other material tools, the human tools also require an elaborate system of domination. The slave does not remain at being a tool forever simply by the fact that they are once taken in. The human things can flee and be out of control unless the owner-master applies a constant enforcement and surveillance over the slave to keep the thing relation. This means that the owner-tool relation of human things already presupposes an institution of property ownership at least between the two principal parties involved. Nevertheless, Hegel's argument may be upheld insofar as we can distinguish the intra-personal relation of human things from the inter-personal relation between two combatants, which exists briefly prior to its degeneration into the former. That is, the moment where, regardless of the instrumentality involved, physical force is actually exercised against others to satisfy the subject's desire to become a bigger and better nourished one.

Despite of the above possibility, Hegelian argument cannot be interpreted in that way because it does not start from the non-sociality situation. In the Hegelian discourse human beings at least do not attack others to "eat" them. They attack them to confirm their superiority over the victims. They do so in the belief that the subjugation of others will accrue the recognition they have sought in the confrontational inter-person relation. ${ }^{25)}$ In the Hegelian discourse, therefore, the subjects, when they actually exert physical force against the other, do so not for their instant self-gratification as is the case with the consumption of food, but for the social reward that follows from it. This means that the subjects live in a society where physical violence against others is an accepted means of providing the recognition that they want to gain.

This inference of ontological priority of the social structure that grants violence the preeminence as the mode of social interactions opens up the possibility that the

25) For Hegel's view of the state of nature, see Axel Honneth, The Struggle for Recognition: The Moral Grammar of Social Conflict (Cambridge: Polity Press, 1995), pp.40-7. 
recognition could also be obtainable from other "victors," if not from the subjugated. That is, the sociality condition does not have to be limited to the two-person relation. If multiplicity of subjects is assumed, another social relation of a different kind that is mediated by violence could be available insofar as there remain other unsubjugated subjects even if some will fall into the two-person relation. This other social relation might provide what the subjects want from it when other remaining victors acknowledge the victor's physical prowess and give due recognition to it. Therefore, it is a certain theoretical possibility of the Hegelian dialectic that the violence-laden society may go on indefinitely, the society wherein violence is the dominant mode of interaction and the subjects' identity is formed around their physical prowess unless there is a mechanism that prevents it from being perpetuated.

This violence mediated social relation has close affinity with the classical realist image of 'the state of nature' and its extrapolation into international politics. The above inference, however, shows clearly that violence is inherent neither in the anarchical structure of international politics, nor derivable from the units' "survival" motives. The violence-ripe anarchy is a socially constructed reality, which originates from the physical embodiedness of actor identity. The physical identity is in turn constituted by a social structure that selects violence as the main medium of interactions. The violent interactions are necessitated by the desire of the subjects to gain recognition. The recognition is what the subjects need to confirm their existence qua physical embodiedness. The anarchy, in short, is a reification of the particular kind of social interactions, originating from the ontological embodiedness of the constituent agents (i.e., states).

The reified nature of social interactions implies that the violence-mediated-relation may have its own logic of existence and is able to regenerate itself unless the subjects are otherwise constituted. For Hegel, however, there is a countervailing mechanism inherent in it. The master-slave-two-person relation lays the seed for the eventual eclipse and displacement of the relation of violence by another material relation. By losing in the battle the slave has bartered his body for life and is now totally reduced to "things," not different from any other material things. For him there is no "interpersonal" relation, only that with material objects; hence, "thing-thing" relation or interaction system mediated by consumable goods. This is not the only relation working in the society, however. On top of it is grafted the hierarchical relation between master and slave: that is, the relation of "subject-thing" or organization system in Luhmann's terminology.

The subject-thing relation does not stand alone either. Because of its maintenance costs, it cannot be maintained only by the master's physical force; it has to evolve into an elaborate institution of property rights, at least in regards to the ownership of slave. 
Without it slave would flee from the master's control at every opportune moment. The slave that can pick up a weapon against the master any time or be out of control if he chooses to do so would not be a slave. The subject-thing relation therefore presupposes a property relation among the masters that shackles the slaves institutionally to put them in servitude forever. Following the logic of Hegelian dialectic, we can assume that establishing such an institution in society is possible only when the masters are already fully constituted individual subjects so that they can contract out the property arrangement without recourse to violence. This means that a "subject-subject" relation (or inter-personal system) already exists among them.

When understood in such an expanded conception of social relations, Hegelian master-slave dialectic, in essence, is no other than a diachronic system theory on the development of human agents (human consciousness in Hegel's terminology) within the universalized social context of the thing-thing relation. To reiterate Hegelian dialectical processes underlying the emancipation, the slave does not remain as a thing indefinitely. As time goes, the slave revolts against the master-imposed thingness by turning "inward." That is, work creates a new subject. The slave regains his subjectivity through the "work" he does against the material objects for the master's consumption, (d). When he realizes the nature of his free will and how his will leads to the transformation of the world, the slave begins to identify himself with the products of his work. He thus embodies himself onto the material objects. Then, his material embodiment is generalized thanks to the institution of private property rights, (e). The universal subjectivity is achieved as each subject is recognized as an embodiment of material object.

From this material embodiment, it is quite plausible to infer, as Marx did, that the emergent social relation among the universal consciousness is an exchange relation in which each subject is identified as an owner of properties. Each is linked to the others only through buying and selling activities of "things"; that is, through the medium of market. What is crucial in Hegel's argument here is not the material embodiment itself, but universal "consciousness" of the subject, toward the achievement of which the work-induced material embodiment is a helpful intermediate stepping stone. For Hegel, the human subject qua the embodiment of universal consciousness, the Geist, is the ultimate terminal stage of human development. In order to be embodied in the pure consciousness, the subject eventually has to take off the material embodiment.

The key to this final transformation lies in the nature of the work-induced material embodiment. In this embodiment, in contrast to previous times, the subject takes on the material objects of its own making to "express" his consciousness (will); the subjectivity 
is not lost to the outer material manifestation. It is the owner of the material embodiment that is recognized by others in interactions; it is not submerged and lost in the latter. At the first interaction, it is likely that the subjectivity is recognized only through a particular material embodiment that is present in the goods. However, the subject cannot help but shed off the outer layer to become pure subjectivity later on. That is because it will be apparent to the participants that an "authorship" (universality) has to be found for the changing material embodiments of the subject. In phenomenological perspective the embodiment cannot remain unchanged; its manifestations are different in time, location, workmanship and in many other aspects as the worker-producer makes goods for exchange. There has to be found a transcendental being whose authorship accounts for the variations of manifest subjectivity. Hegel does not present any other transcendental denominator for the manifest material embodiments than the "pure" subjectivity, to which all the outward expressions accrue ultimately.

This idealistic component of Hegelian dialectic opens up a whole range of different possibilities of social relation in the interaction system. For Hegel, the subjectivity of subject does not have to take on a particular material form in order to become universal (i.e., trade goods), as is the case with Marx. Insofar as the discovery of subjectivity is a matter of phenomenological dialectics, it is very likely that the universality is derived from any kind of objective embodiments, regardless they are material or social, if they can be recognized as such. Even starting from the same premise of the work-induced material embodiment, it does not necessarily follow that the social relation as a whole degenerates into one particular type of relation ("exchange relation") before it reaches the condition which is ripe for the emergence of universality in exchange relation, as Marx postulated in Grundisse. ${ }^{26)}$

If we accept the Hegelian position that what is important in the emancipation is the work-induced embodiment, we can infer that the nature of subject's embodiment will eventually determine what kind of relation is constructed amongst the subjects. Again when we take into consideration the possibility that "work" does not have to take only the form of work-against-material-objects and the possibility that it can take the form of work-for-socially-meaningful-objects (conquest, money-making, respect, etc.) or work-for-pure-aesthetic-objects (music, painting, writing, etc.), we may say that the subject's embodiment will be different in the nature and character, depending upon the type of work that a subject performs. We can also expect that its entailing social relations will be different by the type of embodiment.

26) Karl Marx, Grundrisse: Foundations of the Critique of Political Economy, trans. Martin Nicolaus (New York: Random House, 1973). 
The slave, for instance, may work not for the provision of consumable goods of the master, but for the provision of the master's other personal necessities such as his physical aggrandizement through conquest and aesthetic enjoyment, etc. If the slave thus becomes a private tool of war-making or soldier, he is embodied in the warmaking machine of which he is a component like horse or armory and is recognized as such: that is, as a foot soldier, as an artillery man, etc. The relation established among the functionaries will be that of hierarchy and command. Also in this type of work are present the two crucial functions of work that are necessary for the transformation of human consciousness: the fear of death and the discipline of work. However, this type of work would not lead to the eventual individual emancipation unlike the work against material objects because individual subjectivity in this case is again to be lost in the hierarchical relation. Insofar as the individual functionaries find their embodiment within the war-making machine, they will form a collective identity based upon the aggregate totality, separating their group from other like-groups; hence, no individual identity for the war-machine.

The collective subject can develop into a universal being of a different kind if its subjectivity is discovered in the process of war-making against other collectivities and if the discovered subjectivity is generalized through a reification like the institution of property rights in the case of material embodiment: that is, if a personhood is bestowed upon all the collectivities coexisting side-by-side. There seems to be a factor in this social relation that facilitates the reification process: their master remains an individual subject in the society of masters and they are identified with their master as a part of his embodiment. From this initial dependent embodiment, it is not too far-fetched for us to expect, if we are allowed to follow the Hegelian dialectic of recognition, that the functionaries come to realize the master's dependence on them for his life and property. Their aggregate subjectivity is then equated with the master's. From this codeterminate subjectivity, they may develop into the stage where the master's existence has no crucial relevance to the collective subjectivity and where the master is degenerated into a decorative appendage to the latter. ${ }^{27)}$ This possibility of warrior subjectivity shows that Hegelian dialectic of recognition embraces the classical "reason of state" as a latent theoretical possibility.

In regard to latent possibilities, the same can be said when the slave becomes a personal entertainer of the master. As the slave embodies himself with his aesthetic creations, the master will appreciate his existence as such. Again, the slave is likely to

27) This is what happened in the modern state when "prince" had become the "sovereign" head, an institution of the state. 
realize the force of his will in the process of artistic creations and in due time he is going to be reborn as a being of subjectivity. In this case, however, it seems that his subjectivity is plagued with two crucial structural limitations which might prevent the artist-entertainer from achieving individual universality. The art work relation lacks in the mechanism that permits one to interact with other slave-artisans. As the slave is encapsulated in the master's household, his embodiment (i.e., his artistic creations) cannot be recognized and appreciated by other artisans. How other artisans appraise of his creations becomes unimportant for his existence. For that matter, in fact, other artisans who are better qualified to the role of appraisal than the master have no access to his creations. As long as the slave remains as a property of the master, the appraiser-consumer of his creations is none other than the master whose enjoyment is the sole purpose of his artistic activities. While he is the only one who could recognize the art works and bestow meaningful recognition on the slave, the master is most likely to be preoccupied with other worthy matters suitable to his master status (e.g., military works). In addition, the slave cannot even establish a lasting dependent relation with the master. His creations are essentially for the master's temperament and for the fleeting moments of his enjoyment. Simply satisfying the master's bodily desires including aesthetic one is not likely to lay the foundation upon which a long-lasting relationship is build. ${ }^{28)}$ For the artisan slave, therefore, the dialectical reversal of fortune between the master and the slave is unlikely to happen unless the structural conditions are affected by other factors.

Considering the initial premises of master-slave hierarchical relation and interpersonal subject-subject relation between masters, one possible solution for the structural deficiencies of the art work relation might be the conversion of the master into an artisan. Hence, an artisan society is formed at first in the master's household and generalized across the society ${ }^{29)}$ The key to the conversion lies in forcing the master to take up the chore of artistic creations and realize by himself the joy of it. In the social relations that the slave is born to maneuver, the conversion cannot be coerced by the slave because the slave lacks the coercive force in his hands. It should be the result of ideological inculcation by a sort of education the slave provides for the master. ${ }^{30}$

28) Exception to this might be "love" which Hegel postulates as the foundation of marriage. But he adds that love requires the social institution of marriage and the undeniable evidence of lovemaking, that is, children in order to develop into a lasting relation. Otherwise, love is also only for the fleeting moment of sexual desire. See, Hegel, Phenomenology of Spirit, §456, p.273.

29) Kojève's interpretation of Japanese feudal society is similar to this idea. Alexandre Kojève, Introduction to the Reading of Hegel, trans. James H. Nicholas, Jr. (Ithaca, NY: Cornell University Press, 1980), pp.161-2. ff. 
When civility becomes widespread in the artisan society where aesthetic qualities are valued and the slave artisans who have already embodied those qualities are recognized in that capacity, it would be a short step to extend the civility to the personhood of the slave artisans and to embrace them as an equal being. If this can be done, universal subjectivity is achieved even in the artisan society.

\section{Conclusion: Hegelian Diachronic Systems Theory as Alternative to Deconstructive Theory}

The two alternative scenarios for the achievement of universality certainly do not exhaust the possibilities of social relations. However, they will suffice for the purpose of illustrating the dialectic's heuristic value in conceptualizing various types of social relations that human beings are to construct. The key to the theorization of social relations, particularly if it is to account for the historical transformations of social relations, is to find a concept that inter-mediates the subject's relations with material and social objects. If the subject has a determinate identity, it is argued, its interactions are largely circumscribed in scope and nature and a determinate system is formed. A systemic change therefore is possible only when a new medium of interactions is introduced. For Hegel, the concept of "work" is that particular medium of interaction that transforms the agent into a new type of agent, which eventually creates a new system with a different structure. In short, the ontological priority of the social is the key for the interiorization of the medium variable. Only with it can the systems theory interiorize the mechanism of its own transformation.

While reformulating the Hegelian dialectic of recognition, this paper has attempted to show the heuristic value of postulating a kind of ontological causality of the medium upon the formation of actor-identity. This conceptualization of interaction medium is analogous to "signifier" in language. What the re-conceptualization efforts of Hegelian Master-slave dialectic shows thus is that the interaction medium, like the language signifier, does not determine but only circumscribes the potentialities of agency while the latter's definite identity is formed by the structure of system. In other words, the medium of interaction works as a catalyst for the formation of system and structure. When indeterminate subjects are anchored onto a signifier, the subjects' interactions

30) This is how Nietsche reversed Hegel's master-slave dialectic and explained the emergence of modern self. See, Fredrich Nietzsche, On the Genealogy of Morals, trans. Walter Kaufmann and R. J. Hollingdale (New York: Random House, 1969). 
begin to cluster around a determinate purpose. When a system is formed in the process, the subjects become determinate agents by the constraining force of the system's structure.

What this conceptualization of systems theory means in colloquial sense is that those who use the same tools to make things form a particular relationship among themselves, hence a particular identity (Marx); and those who follow the same rules in their relations form a system, hence a particular identity (i.e., Nardin's concept of practical association ${ }^{31}$ ), etc. The relationship among signifier, agent, and structure, however, is not a causal one. Agent and structure have a dialectical relationship; one does not exist without the other. ${ }^{32)}$ As linguistic signifier is an integral part of signified in language, the interaction medium is related to the structure, which is in turn reproduced by the actions of agent. The signifier is the material upon which agents are constituted. All the dialectical relationships among the components start from the relationship between the signifier and actors. Only in this sense can we say that the signifier of interaction medium is the cause of systemic interactions.

What we have discussed so far suggests an alternative conceptualization of systems in inter-states relations to the one available now (i.e., the realist systems theory), which singles out and universalizes a particular medium of interaction (military capabilities). When we take into consideration other possible media of interaction, we come to know that the realist conception of the system involving states and their military interactions are only a particular case. As an alternative to the realist theory, it is suggested that we can construct a diachronic systems theory based upon Hegelian dialectic of recognition. In re-conceptualizing the dialectic in terms of systems theory, its full potentiality as a comprehensive theory of social relations is revealed.

Theoretically speaking, in the Hegelian diachronic theory three ontologically independent categories which need to be presupposed for the formation of a system (actors, social structure, and social medium of interaction) are dialectically inter-related and their relationship takes a concrete form by the phenomenological and existential category of recognition. Rules and resources, which are constitutive to each other, determine the mode of interaction medium at a particular historical juncture. The determinate medium has formative influence on the constitution of actors. A social system arises when a particular agent type is selected over other latent possibilities of

31) Terry Nardin, Law, Morality, and the Relations of States (Princeton: Princeton University Press, 1983).

32) See, Anthony Giddens, Central Problems in Social Theory: Action, Structures and Contradiction in Social Analysis (Berkeley, CA: University of California Press, 1979), pp.49-130. 
human being in the making.

No material determinism needs to be involved here. What kinds of system emerge from the reduction-cum-reification process is not predetermined by the determinate medium of interaction unlike Marxian historical materialism, but it is dependent upon the way that recognition qua politics is played out in the given rule-resource matrix. As signification in language is always a dialectical process of interpretation between speaker and hearer, the medium of interaction is also the process of "internalization of the external and externalization of the internal" to be a determinate medium. ${ }^{33)}$ Since there is always room for maneuvering and ingenuity on the part of the actors in the dialectical interpretive process, the fundamental human desire (i.e., recognition) has a determinate influence on the latter. In that sense, the human beings qua freewill have the choice for their constitution of themselves and society although, as Marx's famous dictum says, they do so under the given constraints. The world we live is that of our making as Onuf aptly puts it in his book, World of Our Making. ${ }^{34}$

The generative process of recognition opens up the possibility that the world we are living does not have to be the way it is. Insofar as the subjects are embodied in a determinate form, the relations that they construct among themselves are open-ended. Even an artisan society is a definite possibility in the Hegelian diachronic theory, as is the totalitarian command society, not to mention, bourgeois liberal society, aristocratic society and theological society which Hegel have discussed in Phenomenology. These multiple possibilities of human social relations, which the Hegelian diachronic theory reveals, allow us to theorize about the future of international relations differently from the post-modern theorist response to the limitations of the positivistic systems theory although the latter may point to a similar conclusion.

For the post-modernists, politics is ultimately about the identity of individuals and groups as an IR postmodernist defines it. ${ }^{35)}$ International politics, as Richard Ashley observes, is "a practice of the inscription of the dangerous, the externalization and totalization of dangers-all in the name of a social totality that is never really present,

33) Peter Burger and Thomas Luckmann, The Social Construction of Reality: A Treatise in the Sociology of Knowledge (Garden City, NY: Doubleday, 1966).

34) Nicholas Greenwood Onuf, World of Our Making: Rules and Rule in Social Theory and International Relations (Columbia, South Carolina: University of South Carolina Press, 1989).

35) Michael Shapiro defines politics as follows: "Political processes are, among other things, contests over the alternative understanding (often implicit) immanent in the representation practices that implicate action and objects one recognizes and the various spaces-leisure, work, political, private, public-within which persons and things take on their identities." Michael Shapiro, "Textualizing of global politics," in James Der Derian and Michael J. Shapiro, ed., International/Intertextual Relations: Postmodern Readings of World Politics (1989), p.12. 
that always contains traces of the outside within, and that is never more than an effect of the practices by which total dangers are inscribed." ${ }^{36)}$ For the post-modernist, the politics of international relations is contextualized as a knowledge practice that prioritizes the domestic order over the international disorder. The realm of international relations, however, is not just a derivative phenomenon of domestic politics. As the reformulation of the master-slave dialectic shows, the realm is already presupposed in the determination of the identity of state. That is, the existence of others is the underlying motive and the existential mechanism of the constitution of the state. Only through the recognitive relationship which it has with other states is the state constituted as an identity. In short, we may say that the ontological priority of the others (or society) is what differentiates the Hegelian diachronic theory from the postmodernist theory of IR.

When the postmodern IR theory conceives the relationship between I and others, it does so in relational terms. That is, I and others together form a discursive whole. Because differance is essentially difference within the discursive whole, "I" differs from "Others" but it does not differ to the extent that it cannot be grasped within the discursive whole (that is, it is not totally different). As Derrida argues, differance is a deferment within a discursive whole. ${ }^{37)}$ For the postmodernist, therefore, the others are the differed being. Since others are not given independent existence, either they are the reflections of I (or others as they are understood by I), which means that the ontology of postmodernism is still plagued with transcendental idealism. The social discourse is constructed transcendentally from the individual "Is." Or the postmodernist theory has no conception of the radical others except relegating them to the realm of unknowable (that is, international politics in the case of Ashley). In either case it is doubtful that "others" will be given due recognition as an independent other.

Ontologically speaking, postmodern theory takes the subjectiveness of identity and its constructability too literally although they have picked up the right target to attackthat is, political identity-as a political movement. It neglects the material base upon which people live in an "illusion," if they do. Otherwise, they cannot form even a false identity; they become psychopathic. On this ground, postmodernism fails as a "social" theory. It remains as philosophy or literary movement. Analogically speaking, it will not do just to persuade him/her that the tree he/she sees now is not a tree. Rather, give him/her a saw and a hammer. Then, he/she will see it differently. Perhaps, as a house

36) Richard Ashley, "Living on Border Lines: Man, Poststructuralism, and War," ibid., p.304.

37) See, Jacques Derrida, Of Grammatology, trans. Gayatri Chakrvorty Spivak (Baltimore: The Johns Hopkins University Press, 1976). 
or a swing, etc. Only then is it possible for the observer to conceptualize him/her as an architect or a carpenter, etc. He/she in turn enacts the conception into reality or vice versa. In contrast, Hegelian diachronic systems theory starts from radical separation and difference between I and others (i.e., the struggle for recognition in the state of nature); then it moves into the relational "Otherness" constituted by the property relations and eventually to the stage of reciprocal recognition. Thus, it is not only more comprehensive than the postmodernist discourse analysis, but also it identifies the generative mechanism accounting for the identity politics (i.e., the dialectic of recognition). Only when a social theory is equipped with the generative mechanism can it explain the change of identity coherently. Otherwise, as is the case with the postmodernist theory, the change itself is explained in an ad hoc way or as the outcome of the identity struggle, in case of which the model is too conflict-laden. By investigating available media of interaction and entailing potential transformations in actor identity existing structures, the proposed diachronic systems theory provides us with the matrix of developmental possibilities, according to which we can gauge actual social developments. It thus makes the actualized form of society both understandable and explainable systematically, which is the only goal that any social theory can possibly pursue. 


\section{REFERENCES}

Ashley, Richard. "Living on Border Lines: Man, Poststructuralism, and War," in Der Deian, James, and Michael J. Shapiro, eds. International/Intertextual Relations: Postmodern Readings of World Politics. Lexington, MA: Lexington Books, 1989.

Burger, Peter and Thomas Luckmann. The Social Construction of Reality: A Treatise in the Sociology of Knowledge. Garden City, NY: Doubleday, 1966.

Buzan, Barry, Charles Jones, and Richard Little. The Logic of Anarchy: Neorealism to Structural Realism. New York: Columbia University Press, 1993.

Dallmayr, Fred R. G. W. F. Hegel: Modernity and Politics. Newbury Park. California: Sage, 1993.

Derrida, Jacques. Of Grammatology, trans. Gayatri Chakrvorty Spivak. Baltimore: The Johns Hopkins University Press, 1976.

Fay, Brian. Contemporary Philosophy of Social Sciences: A Multicultural Approach. Cambridge. Mass.: Blackwell, 1996.

Giddens, Anthony. Central Problems in Social Theory: Action, Structures and Contradiction in Social Analysis. Berkeley, CA: University of California Press, 1979.

Hegel, G. W. F. Philosophy of Right. trans. T. M. Knox. London: Oxford University Press, 1967.

Phenomenology of Spirit. trans. A. V. Miller. Oxford: Oxford University Press, 1977.

Hoffman, Piotr. Violence in Modern Philosophy. Chicago, Illinois: The University of Chicago Press, 1989.

Hollis, Martin, and Steve Smith. Explaining and Understanding International Relations. New York: Oxford University Press.

Honneth, Axel. The Struggle for Recognition: The Moral Grammar of Social Conflict. Cambridge: Polity Press, 1995.

Hyppolite, Jean. Genesis and Structure of Hegel's Phenomenology of Spirit. Trans. Samuel Cherniak and John Heckman. Evanston, Illinois: Northwestern University Press, 1974.

Keohane, Robert O. ed. Neorealism and Its Critics. New York: Columbia University of Press.

Kojève, Alexandre. Introduction to the Reading of Hegel, trans. James H. Nicholas, Jr. Ithaca. NY: Cornell University Press, 1980. 
Kratochwil, Friedrich. "On System, Boundaries, and Territoriality: An Inquiry into the Formation of the State System.” World Politics, vol.39-1 (January, 1986)

Laclau, Ernesto, and Chantal Mouffe. Hegemony and Socialist Strategy: Toward a Radical Democratic Politics. Trans. Winston Moore and Paul Cammack. London: Verso, 1985.

Lakatos, Imre, and Alan Musgrave, eds. Criticism and the Growth of Knowledge. Cambridge: Cambridge University Press, 1970.

Layder, Derek. The Realist Image in Social Science. New York: St. Marin's Press, 1990.

Linklater, Andrew. "Marxism" in Scott Burchill and Andrew Linklater. eds., Theories of International Relations. New York: St. Martin Press, 1996.

Luhmann, Niklas. The Differentiation of Society. trans. Stephen Holmes and Charles Larmore. New York: Columbia University Press, 1982.

Social Systems. trans. John Bednarz Jr. and Dirk Baecker. Stanford, CA: Stanford University Press, 1995.

Marx, Karl. Grundrisse: Foundations of the Critique of Political Economy. trans. Martin Nicolaus. New York: Random House, 1973.

Nardin, Terry. Law, Morality, and the Relations of States. Princeton: Princeton University Press, 1983.

Neufeld, Mark A. The Restructuring of International Relations Theory. Cambridge: Cambridge University Press, 1995.

Nietzsche, Fredrich. On the Genealogy of Morals. Trans. Walter Kufmann and R. J. Hollingdale. New York: Random House.

Onuf, N. G. World of Our Making: Rules and Rule in Social Theory and International Relations. Columbia, SC: University of South Carolina Press, 1989.

Redding, Paul. Hegel's Hermeneutics. Ithaca, NY: Cornell University Press, 1996.

Ruggie, J. G. "Continuity and Transformation in the World Politics: Toward a Neo Realist Synthesis." World Politics, vol.35-2 (Summer 1983)

Shapiro, Michael. "Textualizing of global politics," in Der Derian, James and Michael J. Shapiro, eds. International/Intertextual Relations: Postmodern Readings of World Politics. Lexington, MA: Lexington Books, 1989.

Taylor, Charles. Philosophical Arguments. Cambridge: Harvard University Press, 1995. Hegel. Cambridge: Cambridge University Press, 1975.

Waldron, Jeremy. The Right to Private Property. Oxford: Clarendon Press, 1988. 
Waltz, Kenneth. Theory of International Politics. Massachusetts: Addison-Wesley Publishing Company, 1979.

"Reflections on Theory of International Politics: A Response to my Critics," in Koehane, R. O. Neorealism and Its Critics. New York: Columbia University Press, 1986.

Wendt, Alexander. "The Agent-Structure Problem in International Relations Theory." International Organization, vol.41-3 (September, 1987)

Williams, Robert R. Recognition: Fichte and Hegel on the Other. Albany, NY: State University of New York Press, 1992. 